\title{
Coverage of tobacco control in Jordanian newspapers: implications for strengthening the role of news media
}

Rasha K. Bader ${ }^{7}$, Aisha S. Shtaiwi ${ }^{7}$, Rawan A. Shihab ${ }^{1}$, Nour A. Obeidat ${ }^{7}$ and Feras I. Hawari ${ }^{1}$

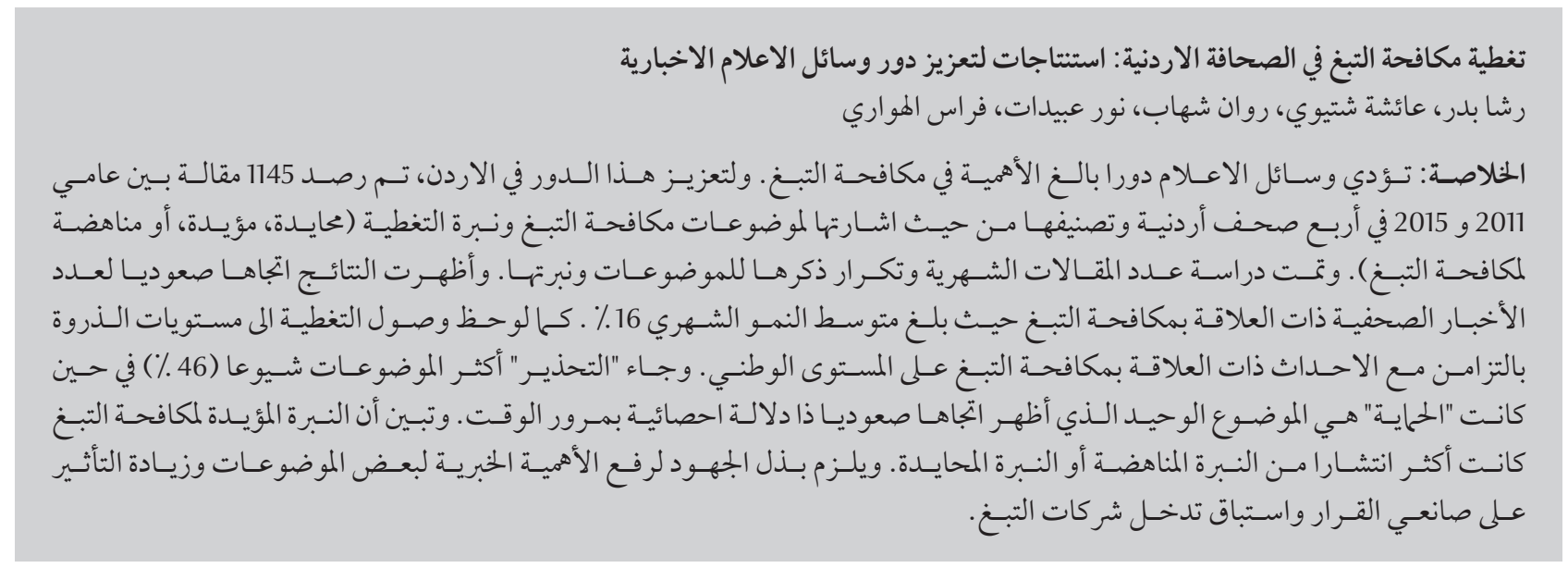

ABSTRACT News media play a critical role in tobacco control. To strengthen this role in Jordan, four newspapers were searched and 1145 articles between 2011 and 2015 were coded for mention of MPOWER topics and for tone of coverage (neutral, pro-, or anti-tobacco control). Monthly counts, mention of tobacco control topics and the tones were examined. The monthly count of tobacco control-related news items showed an upward trend with an average monthly growth of $16 \%$. Peaks in coverage were observed in synchrony with national tobacco control developments. 'Warn' was the topic most frequently mentioned (46\%). 'Protect' was the only topic that showed a statistically significant upward trend over time. A pro-tobacco control tone was more prevalent than an antitobacco control or neutral tone. Thus, efforts are needed to enhance the newsworthiness of certain topics, boost influence on decision-makers and pre-empt industry interference.

Couverture de la lutte antitabac dans les journaux jordaniens : implications pour le renforcement du rôle des médias d'information

RÉSUMÉ Les médias d'information jouent un rôle crucial dans la lutte antitabac. Afin de renforcer ce rôle en Jordanie, quatre journaux ont été étudiés et 1145 articles publiés entre 2011 et 2015 ont été codés lorsqu'ils comportaient la mention du programme MPOWER et pour le ton de la couverture (neutre, pour ou contre la lutte antitabac). Les décomptes mensuels, les mentions de sujets relatifs à la lutte antitabac et les tons ont été passés en revue. Le nombre mensuel d'articles traitant de la lutte antitabac a montré une tendance à la hausse, avec une croissance mensuelle moyenne de $16 \%$. Des pics dans la couverture ont été observés de façon synchrone avec les nouveautés liées à la lutte antitabac au plan national. Les mises en garde étaient le sujet mentionné le plus fréquemment (46\%). La protection était le seul sujet qui affichait une tendance à la hausse significative au cours du temps. Un ton en faveur de la lutte antitabac était plus prévalent qu'un ton défavorable à la lutte antitabac ou un ton neutre. Des efforts sont donc requis pour renforcer la crédibilité de certains sujets, accroître l'influence sur les décideurs politiques, et anticiper l'ingérence de l'industrie du tabac. 


\section{Introduction}

News media play a crucial role in influencing health practices and health policy (1). Specifically, in the context of tobacco control, news media can play a critical and complex role beyond disseminating information $(1,2)$. News media can shape policy-makers' stance and public perception: the emphasis news media place on tobacco control influences the priority afforded to the issue, and their framing influences perceptions of the problem and of its potential solutions (1-6). In addition, news media coverage may also be considered a reflection of the newsworthiness of tobacco control developments and events, where increasing coverage reflects a rise in the number of events deemed newsworthy (1).

Accordingly, strengthening the role of the news media in tobacco control is crucial, particularly when mass media campaigns are scarce (1). Efforts that contribute to increasing the newsworthiness of tobacco control and influencing the framing of news coverage may take several forms, including generating and pushing content, holding forums such as press conferences, and maintaining open communication channels with reporters $(1,2,4)$.

Jordan is an Eastern Mediterranean country that is heavily burdened with tobacco use. The prevalence among adult males approaches 50\% (7) and 34\% of boys (aged 13-15 years) currently use some form of tobacco product (8). Despite ratifying the Framework Convention on Tobacco Control in 2004 (9), Jordan still lags behind countries of the region and the world in enforcing measures that could address the epidemic, including the use of mass media campaigns which are non-existent in Jordan $(7,10)$.

Under these circumstances, there arises a need to strengthen the role that news media play in tobacco control in Jordan. Such strengthening should build on an understanding of the status quo and align with the national tobacco control priorities. Given the lack of research that describe the coverage of the news media of tobacco control in Jordan, and taking into consideration that the coverage by television, radio and electronic media parallels that of newspapers $(6,11,12)$, this study sought to characterize the coverage of tobacco control by newspapers to provide a base on which to build. Specifically, we examined the responsiveness of newspapers to tobacco control developments, the newsworthiness of specific tobacco control topics and the tone displayed in the coverage of tobacco control topics. While there are no studies from the region to compare with, our work benefits from those conducted in other parts of the world (4,12-14).

\section{Methods}

\section{Design and sample}

As part of the day-to-day operations, the Cancer Control Office at King Hussein Cancer Center conducted daily monitoring of the 3 most-read (IPSOS Stat, Personal communication, March 2016) Jordanian Arabic newspapers Alrai, Alghad, and Addustour as well as the English affiliate of Alrai - The Jordan Times. A trained employee of the Cancer Control Office used the PDF versions of these newspapers to identify news items covering tobacco control. This was done through searching for the following keywords on a daily basis: tobacco, cigarette(s), smoking, smoker(s), smoke and waterpipe (the corresponding Arabic words were used, except when searching the The Jordan Times). All items generated by the search were logged into a database. We included 1145 tobacco-related news items that were published during the period 1 October, 2011 to 31 March, 2015 (42 months).

In parallel, and to assist with the analysis of the responsiveness to events, the Cancer Control Office kept a monthly log of tobacco control developments. Specifically, the Cancer Control Office logged events in the field of tobacco control that received coverage and mention by the logged news items.

\section{Measures}

For the purpose of this study, the Cancer Control Office developed a coding scheme (described in detail in Table 1) that benefited from the experience of others $(6,12,14)$. Building on knowledge and involvement in tobacco control, and after receiving comprehensive training on the coding scheme, a primary coder conducted coding of all logged items. To test for subjectivity, a second coder performed blinded coding of a randomly-selected $10 \%$ sample of the items. The inter-coder reliability was assessed using the kappa statistic with results indicating substantial agreement between the 2 coders (a median kappa value of 0.73) (15). Given this level of agreement, coding results as generated by the primary coder were used for the analysis.

\section{Analysis}

We used Microsoft Excel 2010 to generate descriptive statistics and plots. To understand temporal effects, we tallied and plotted monthly counts of tobacco control-related news items.

To characterize newspaper coverage in terms of the newsworthiness of tobacco control topics modelled after the MPOWER policies (Monitor, Protect, Offer, Warn, Enforce, Raise) (16), we calculated and plotted the monthly "Share of Coverage" (SoC) for the various policies and for additional topics of interest (namely the waterpipe, and minors and tobacco). SoC, a term used in the field of public relations, refers to the "measurement of total earned, or nonpaid, media coverage in print, broadcast, and Internet channels devoted to the particular industry or topic as analysed to determine what per cent of outputs is devoted to a client or product" (17). 


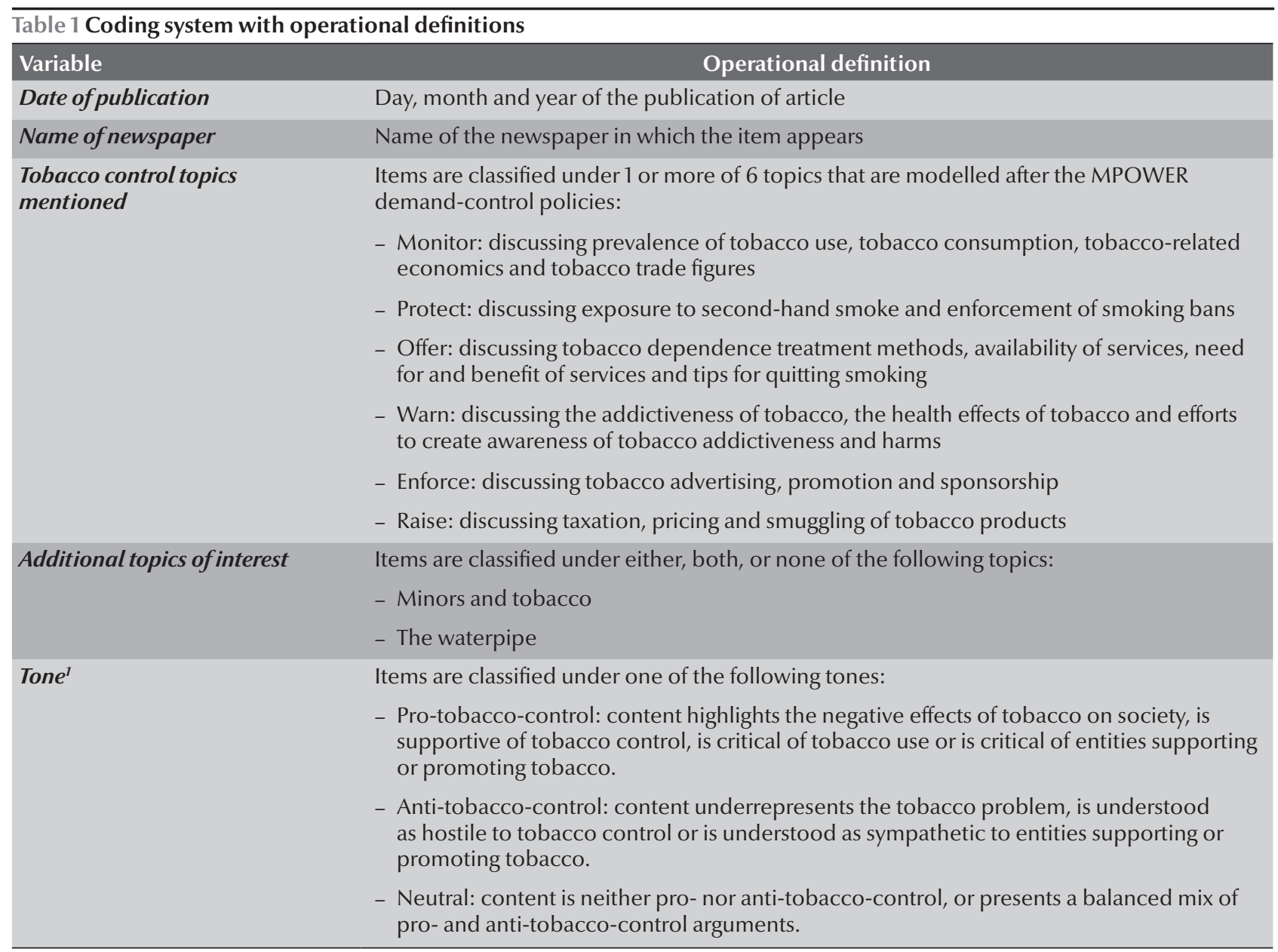

${ }^{1}$ Coding for tone was performed for a subset of the items (published between 1 April, 2014 and 31 March, 2015).

For our analysis, we adapted the term $\mathrm{SoC}$ to refer to the percentage of news items mentioning a specific tobacco control topic independent of their mention of other topics (i.e. the SoC for the 6 tobacco control topics in a certain month are not mutually exclusive and the monthly sum of SoCs can add up to more than a $100 \%$ ). For example, in March 2015, 38 tobacco-related items were published in the newspapers. Of those, 7 mentioned Monitor (18\%), 15 mentioned Protect (39\%), 3 mentioned Offer (8\%), 20 mentioned Warn (53\%), 2 mentioned Enforce (5\%) and there was no mention of Raise (0\%). We used ANOVA to analyse changes over time; $P<0.05$ was considered statistically significant.
We also calculated the split of items across 3 tones, pro-tobacco control, anti-tobacco control and neutral.

\section{Results}

Despite variations, the monthly count of news items related to tobacco control showed an average monthly growth of $16 \%$. Figure 1 shows an upward trend in monthly counts and highlights events corresponding to increasing coverage (as entered in the log of events).

Warn was the tobacco topic most frequently mentioned over the study period, with almost 1 in every 2 news items mentioning it [mean SoC $46 \%$, standard deviation (SD) 14\%]. This was followed by Protect (mean SoC 30\%, SD 18\%), Monitor (mean SoC 22\%,
SD 12\%), Offer (mean SoC 15\%, SD 11\%), Raise (mean SoC 14\%, SD 13\%), and Enforce (mean SoC 4\%, SD 5\%). As depicted in Figure $2 \mathrm{~A}-\mathrm{F}$, an upward trend was noticeable for SoC over time for all tobacco control topics with the exception of Offer. However, this upward trend was significant only in the case of Protect $(P=0.02)$. With regards to additional topics, the average SoC for waterpipe was $11 \%$ rising to more than 50\% during January-March 2014 and the average SoC for minors and tobacco was $7 \%$ rising to $35 \%$ during March 2014.

For the period during which items were coded for tone, more than half of the news items (55\%, 191/347) showed a pro-tobacco control tone, 35\% (123/347) exhibited a neutral tone and only $10 \%$ 


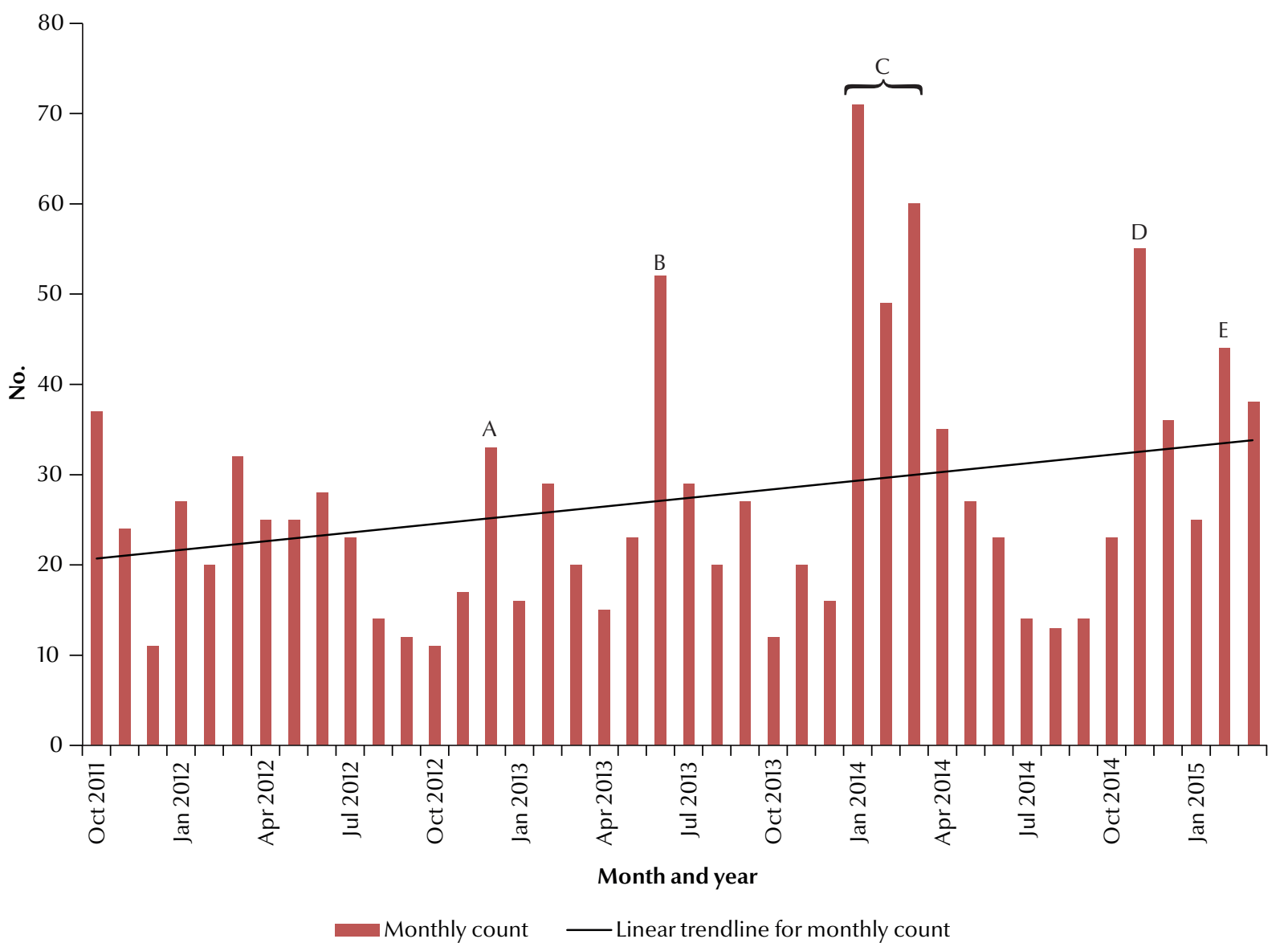

A. Dec 2012: The tobacco industry in Jordan lowered cigarette prices.

B. Jun 2013: The first comprehensive report on the status of tobacco control in Jordan was released, tobacco-display regulations were released, the winners of the tobacco control media contest were announced, and smoke-free certificates were awarded to local organizations.

C. Jan - Apr 2014: The Government decided to ban licensing of waterpipe in cafes and restaurants by Mar 31st. The decision faced fierce resistance from the hospitality industry. The deadline lapsed without tangible action.

D. Nov 2014: Lung Cancer Awareness Month and the decision of the FCTC Conference of the Parties (FCTC/COP) to form a committee to address the regulation of the e-cigarette (Electronic Nicotine Delivery Systems - ENDS).

E. Feb 2015: The World Cancer Day was marked by focusing on tobacco as a prominent risk factor.

(34/347) exhibited an anti-tobacco control tone. However, $43 \%$ of the articles mentioning Raise exhibited an anti-TC tone.

\section{Discussion}

This paper attempts to characterize newspaper coverage of tobacco control in Jordan. To the best of our knowledge, no other systematic efforts specific to Jordan or the region have been undertaken and shared in the literature, but similar studies from other parts of the world are available $(4,12-14)$. We propose that other countries of similar circumstances may benefit from our experience.

As demonstrated through the synchrony between the spikes in the monthly counts and the tobacco control events recorded in the monthly log, our data indicate the responsiveness of newspapers to tobacco control events. Figure 1 highlights several spikes and the corresponding events giving rise to these spikes. For example, the surge in count of January 2014 (the most prominent) came in response to a decision of the government to ban serving waterpipes in cafes and restaurants. This surge in count was also accompanied by a surge of SoC for Protect, minors and tobacco, and waterpipe, which might be expected given the nature of the event.

However, our results indicate a variation in the level of attention awarded to the various tobacco control topics and suggest a reliance on triggers for coverage. While certain topics such as Warn and Protect seem to receive a lot of attention (Figure 2), others, such as Enforce and Offer, do not receive the same level of attention. In the case of Protect, the continuous presence of triggers helped coverage grow over time (several events took place including the 

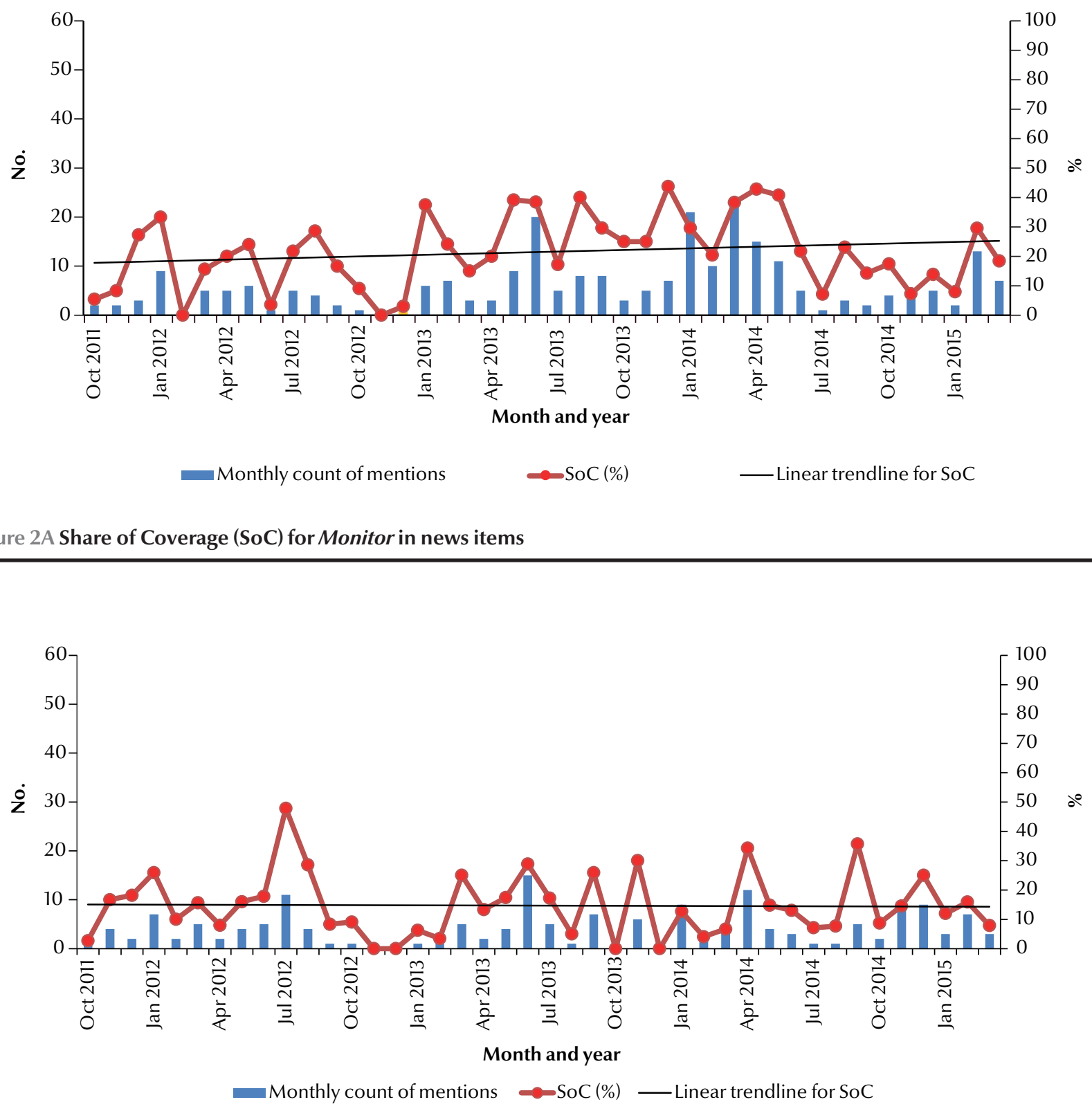

Figure 2B Share of Coverage (SoC) for Protect in news items

proposed waterpipe ban in restaurants and cafes, several attempts to enforce nonsmoking zones in restaurants, and the demands for banning smoking at the Parliament). However, in the absence of specific events to direct coverage, we speculate that newspapers are more inclined to report readily available material (i.e. disseminating information which would usually fall under Warn) compared to covering topics that may be considered more complex (e.g. Offer).
Ourresultssuggest that tobaccocontrol advocates in Jordan may be missing opportunities to shape policy-makers' stance and influence public support. For example, examining the coverage of January 2014 and the following months suggests that tobacco control advocates could have better utilized the newsworthiness awarded to the decision to ban waterpipes in restaurants and cafes in order to influence the position of decision-makers (potentially leading to the enforcement of the decision) and the public (potentially leading to sustained newsworthiness of the failure to enforce the decision). Consequently, the deadline of 31 March, 2014 (set by the government to put the decision into effect) lapsed without tangible action, suggesting that the efforts of tobacco control advocates were insufficient to counter the fierce resistance that the tobacco industry demonstrated - at times channelled through the Parliament. Accordingly, following 3 months of extensive coverage (January-March 
2014), newsworthiness for Protect (Figure 2B) lost traction from April 2014.

As for tone, while the majority of items were pro-tobacco control, an antitobacco control tone was prevalent in items mentioning Raise. At times, this tone was a result of the dissemination of industry-commissioned research (articles in Arabic available upon request). These findings are in line with previous research describing the industry's success in gaining consistent coverage of selected issues, and highlighting economic topics among those that receive the most anti-tobacco control coverage $(1,18)$.

Tobacco control advocates and professionals in Jordan may build on these findings to strengthen the contribution of news media to advancing tobacco control. Advocates should build on the responsiveness of the media to events and aim to create triggers to help address topics that have not been receiving sufficient coverage, namely Enforce, Offer and Raise. As Jordan continues to lag behind on enforcement of tobacco advertising and promotion bans (7), the media can play a crucial role in advocating for stricter measures. Likewise, in a country where there is high interest in quitting tobacco use but only $2.4 \%$ of smokers have ever utilized a tobacco dependence treatment service (19), the media should be more engaged in advocating for the expansion of tobacco dependence treatment services. Similarly, in a country where, despite inflation, there has been no increase in cigarette real prices since 2008 (20,21), the media can play a pivotal role in supporting the argument for higher prices
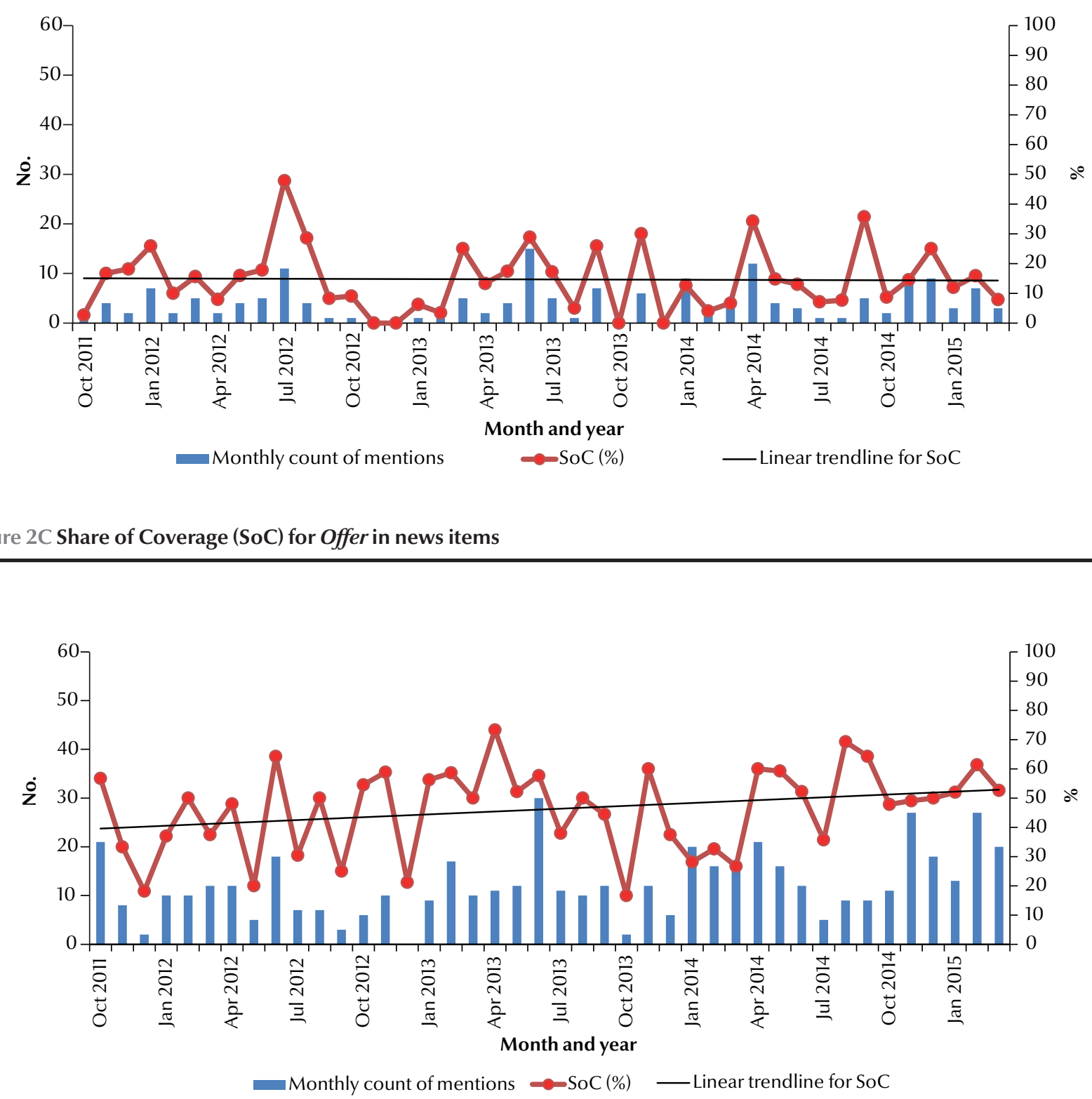

Figure 2D Share of Coverage (SoC) for Warn in news items 

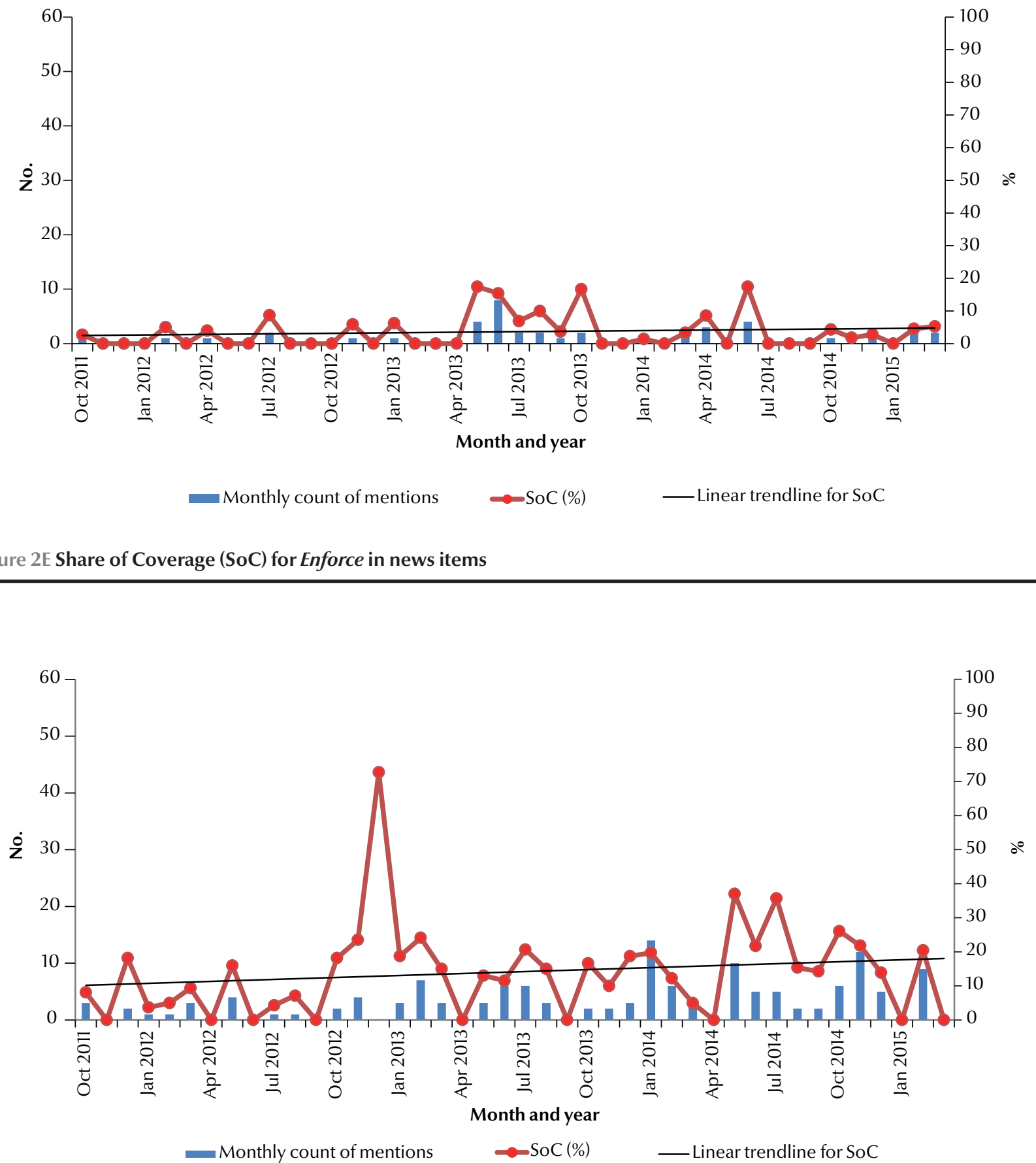

Figure 2F Share of Coverage (SoC) for Raise in news items

of tobacco products. To further support newsworthiness of these triggers, tobacco control advocates and professionals should aim to create capacitybuilding opportunities that allow media newspersons to learn more about the different MPOWER policies and the national priorities in tobacco control in order to help achieve improved coverage (22). In parallel, tobacco control advocates should exert efforts to strategically build on newsworthiness to better influence the stance of decisionmakers and the public.

Advocates should also be aware of tobacco industry attempts to disrupt pro-tobacco control news media coverage, as has been the case elsewhere
$(1,23)$. At a time when Jordanian print media is facing financial problems, the threat of interference becomes even more significant $(24,25)$. Accordingly, interventions that address both contributors and editors-in-chief may also be of value in Jordan to influence the framing and tone of tobacco control media coverage and pre-empt interference. 
Our study has its limitations. First, we focused our analysis on newspapers, one of many media outlets. However, studies have found newspaper coverage to correlate highly with the coverage of other media outlets, including radio, television and electronic media $(6,11,12)$. Accordingly, newspapers are considered by researchers as the official record for news events (1). Yet, an area that is worth exploring and that was not within the scope of this study is social media, which could be more relevant for certain topics and certain populations (e.g. youth) (13). While a relatively new field for research, more and more studies are attempting to understand news coverage by social media (2,26). Second, by virtue of our methods (human coding), our results may be prone to some subjectivity. Nevertheless, we sought to minimize this by the inclusion of a second coder to conduct blinded coding on a random sample, subsequently testing for coding reliability (27). Finally, our analysis is descriptive in nature. More in-depth research can help explore the accuracy, context and prominence of messages, and the reach to target audience(s) $(17,28)$. In addition, further qualitative coding that was not available in this study could introduce measures to track sources of articles (e.g. tobacco industry, journalists, tobacco control activists) in an attempt to characterize content in relation to its sources with the aim of generating recommendations for advocacy efforts. $(17,28)$.

In conclusion, Jordanian newspapers demonstrate responsiveness to and reliance on events as triggers, and a general newsworthiness of tobacco control. Yet, our results indicate that not all tobacco control topics are equal in the eyes of the media. While coverage is mostly neutral or pro-tobacco control, an anti-tobacco control tone is more prominent on specific topics. Tobacco control advocates may build on these findings to enhance the role of news media in advancing tobacco control.

\section{Funding: None.}

Competing interests: None declared.

\section{References}

1. National Cancer Institute. The Role of the Media in Promoting and Reducing Tobacco Use. Tobacco Control Monograph No. 19. Bethesda, MD: U.S. Department of Health and Human Services, National Institutes of Health, National Cancer Institute. NIH Pub. No. 07-6242, June. 2008.

2. Hammond D, Wakefield M, Durkin S, Brennan E. Tobacco packaging and mass media campaigns: research needs for Articles 11 and 12 of the WHO Framework Convention on Tobacco Control. Nicotine Tob Res. 2013;15(4):81731.

3. Harris JK, Shelton SC, Moreland-Russell S, Luke DA. Tobacco coverage in print media: the use of timing and themes by tobacco control supporters and opposition before a failed tobacco tax initiative. Tob Control. 2010;19(1):37-43.

4. Llaguno-Aguilar SE, Dorantes-Alonso Adel C, Thrasher JF, Villalobos V, Besley JC. Analisis de la cobertura del tema de tabaco en medios impresos mexicanos [Analysis of coverage of the tobacco issue in Mexican print media]. Salud Publica Mex. 2008;50 Suppl 3:S348-54.

5. Smith KC, Terry-McElrath Y, Wakefield M, Durrant R. Media advocacy and newspaper coverage of tobacco issues: a comparative analysis of 1 year's print news in the United States and Australia. Nicotine Tob Res. 2005;7(2):289-99.

6. Stillman FA, Cronin KA, Evans WD, Ulasevich A. Can media advocacy influence newspaper coverage of tobacco: measuring the effectiveness of the American stop smoking intervention study's (ASSIST) media advocacy strategies. Tob Control. 2001;10(2):137-44.

7. WHO report on the global tobacco epidemic 2015: Raising taxes on tobacco. Geneva: World Health Organization; 2015.

8. WHO Regional Office for the Eastern Mediterranean and the Centers for Disease Control and Prevention. Global youth tobacco survey. Country reports. http://www.emro.who. int/images/stories/tfi/documents/GYTS_CR_JOR_2009. pdf?ua=1, accessed 25 February 2017) [in Arabic].

9. United Nations Treaty Collection. WHO Framework Convention on Tobacco Control [webpage]. (https://treaties. un.org/pages/ViewDetails.aspx?src=TREATY\&mtdsg_no=IX$4 \&$ chapter=9\&clang=_en, accessed November 2016).
10. [Status quo of tobacco control in Jordan]. Amman: King Hussein Cancer Foundation/King Hussein Cancer Center; September 2013 (http://www.khcf.jo/PDF/Status\%20Quo\%20 of\%20TC\%20Report.pdf, accessed 25 February 201) [In Arabic].

11. National Cancer Institute. Evaluating ASSIST: A blueprint for understanding state-level tobacco control. Tobacco Control Monograph No. 17. Bethesda, MD: U.S. Department of Health and Human Services, National Institutes of Health, National Cancer Institute. NIH Pub. No. 06-6058, October 2006.

12. Gao J, Chapman S, Sun S, Fu H, Zheng P. The growth in newspaper coverage of tobacco control in China, 2000-2010. BMC Public Health. 2012;12:160.

13. Dorfman L. Studying the news on public health: how content analysis supports media advocacy. Am J Health Behav. 2003;27 Suppl 3:S217-26.

14. McGee R, Bang S, Marsh L. Newspaper coverage of tobacco control in New Zealand. Aust N Z J Public Health. 2014;38(3):265-9.

15. Viera AJ, Garrett JM. Understanding interobserver agreement: the kappa statistic. Fam Med. 2005;37(5):360-3.

16. World Health Organization. Tobacco Free Initiative (TFI). MPOWER [webpage] (http://www.who.int/tobacco/mpower/en/, accessed 8 February 2017).

17. Exploring the link between volume of media coverage and business outcomes. Jeffrey A, Michaelson D, Stacks D. Gainesville, FL: Institute for Public Relations (http://www.instituteforpr.org/wp-content/uploads/Media_Coverage_Business06. pdf, accessed 25 February 2017).

18. Clegg Smith K, Wakefield M, Edsall E. The good news about smoking: how do U.S. newspapers cover tobacco issues? J Public Health Policy. 2006;27(2):166-81.

19. Jaghbir M, Shareif S, Ahram M. Quitting smoking and utilization of smoking cessation services in Jordan: a populationbased survey. East Mediterr Health J. 2014;20(9):538-36.

20. Eriksen M, Mackay J, Schluger N, Islami F, Drope J. The tobacco atlas. Fifth edition. Atlanta, GA: American Cancer Society; 2015 
(http://3pk43x313ggr4cy0lh3tctjh.wpengine.netdna-cdn. com/wp-content/uploads/2015/03/TA5_2015_WEB.pdf, accessed 25 February 2017).

21. CIA. The World Factbook. Middle East. Jordan (https://www cia.gov/library/publications/the-world-factbook/geos/ jo.html, accessed 25 February 2017).

22. FCTC. Guidelines for implementation of Article 12. Guidelines on education, communication, training and public awareness (http://www.who.int/fctc/guidelines/adopted/article_12/ en/, accessed 25 February 2017).

23. Muggli ME, Hurt RD, Becker LB. Turning free speech into corporate speech: Philip Morris' efforts to influence U.S. and European journalists regarding the U.S. EPA report on secondhand smoke. Prev Med. 2004;39(3):568-80.

24. The plight of Jordan's newspapers. Ventura. 2014 (http://

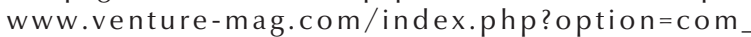
k2\&view=item\&id=604:the-plight-of-jordan\%E2\%80\%99snewspapers\&Itemid=14, accessed September 2015).
25. House schedules meeting to discuss print media troubles. The Jordan Times. 30 March 2015 (http://vista.sahafi.jo/art.php?id $=559 \mathrm{~b} 5 \mathrm{ea} 5 \mathrm{~b} 0847 \mathrm{a} 07 \mathrm{~b} 6006 \mathrm{cee} 2 \mathrm{e} 32 \mathrm{ab} 54 \mathrm{ebaec} 3 \mathrm{~d}$, accessed 25 February 2017).

26. Kim Y, Huang J, Emery S. Garbage in, garbage out: data collection, quality assessment and reporting standards for social media data use in health research, infodemiology and digital disease detection. J Med Internet Res. 2016;18(2):e41.

27. Macnamara J. Media content analysis: Its uses; benefits and best practice methodology. Asia Pacific Public Relations Journal. 2005;6(1):1-34.

28. Michaelson D, Griffin TL. A new model for media content analysis. Gainesville, FL: Institute for Public Relations; 2005 (http://www.instituteforpr.org/wp-content/uploads/MediaContentAnalysis.pdf, accessed 25 February 2017). 